\title{
Valor nutritivo de silagens de milho (Zea mays L.) produzidas com inoculantes enzimo-bacterianos ${ }^{1}$
}

\section{Karina Dosualdo Rocha ${ }^{2}$, Odilon Gomes Pereira ${ }^{3}$, Sebastião de Campos Valadares Filho ${ }^{3}$, Amanda Prates de Oliveira ${ }^{4}$, Leonardo Bruno de Bastos Pacheco ${ }^{5}$, Fernanda Helena Martins Chizzotti ${ }^{6}$}

\author{
${ }^{1}$ Parte da Dissertação da primeira autora apresentada ao Programa de Pós-Graduação em Zootecnia - UFV. \\ 2 Mestre em Zootecnia - UFV. \\ ${ }^{3}$ Departamento de Zootecnia - UFV. Bolsista do CNPq. \\ 4 Pós-graduação - UNESP - Jaboticabal. \\ 5 Graduação em Agronomia - UFV \\ ${ }^{6}$ Doutoranda em Zootecnia - UFV.
}

RESUMO - Este trabalho foi desenvolvido a partir de dois experimentos. No primeiro, avaliaram-se o pH, a relação nitrogênio amoniacal/nitrogênio total $\left(\mathrm{N}-\mathrm{NH}_{3} / \mathrm{Ntotal}\right)$, a composição química e a digestibilidade in vitro da matéria seca (DIVMS) de silagens de milho produzidas ou não com inoculantes enzimo-bacterianos, utilizando-se silos laboratoriais. Adotou-se um arranjo fatorial $6 \times 3$, composto por seis períodos de fermentação $(1,3,7,14,28$ e 56 dias) e três inoculantes (um controle e dois inoculantes comerciais), em um delineamento inteiramente casualizado, com três repetições. Avaliaram-se os seguintes inoculantes microbianos: controle (sem inoculante), Maize All (Alltech do Brasil) e Biomax (Christian Hansen). Constatou-se efeito da interação inoculante $\times$ período sobre o teor de MS, registrando-se maiores valores para as silagens inoculadas, independentemente do período de fermentação. O teor de PB foi influenciado pelo inoculante, registrando-se menor valor (6,23\%) para a silagem não tratada. Para os teores de FDN e FDA, observou-se efeito apenas de período, estimando-se decréscimos de 0,302353 e 0,063321 unidades/dia de fermentação, respectivamente. A DIVMS também foi influenciada apenas pelo período, estimando-se incrementos de 0,0546305 unidades/dia de fermentação. No segundo experimento, avaliaram-se o consumo e a digestibilidade aparente total dos nutrientes das silagens do experimento 1, utilizando-se 18 ovinos adultos, castrados, distribuídos em três tratamentos, segundo um delineamento em blocos casualizados, com seis repetições. Adotou-se relação volumoso:concentrado de 90:10, com base na matéria seca. O consumo dos nutrientes não foi influenciado pelas dietas experimentais, registrando-se valores médios de 1,$26 ; 0,14$ e $0,84 \mathrm{~kg} / \mathrm{dia}$ para os consumos de MS, PB e NDT, respectivamente. Para a digestibilidade aparente total dos nutrientes, detectou-se efeito de inoculante somente para a PB, observando-se maior valor para a silagem tratada com o inoculante Biomax (66,0\%). A adição de inoculantes à planta de milho não promoveu alterações na composição química e no consumo dos nutrientes das silagens.

Palavras-chave: consumo, digestibilidade, nitrogênio amoniacal, $\mathrm{pH}$

\section{Nutritive value of cornsilage (Zeamays L.) produced with enzymatic-bacterial inoculants}

ABSTRACT - Two inoculated corn silage experiments are reported. In the first one, $\mathrm{pH}$ value, ammonia nitrogen in total nitrogen (N-NH3/Total N), chemical composition and in vitro drymatter digestibility of corn silages with or without enzymatic-bacterial inoculants were evaluated in laboratory silos. A $6 \times 3$ factorial arrangement of treatments, with six fermentation periods $(01,03,07,14,28$ and 56 days) $\mathrm{x}$ three inoculants (control and two commercial inoculants: Maize All (Alltech of Brazil) and Biomax (Christian Hansen) was used in a completely randomized design, with three replications. Effect of the inoculant $\times$ fermentation period interaction was detected on silages DM content, larger values corresponding to the inoculated silages, independent of the fermentation period. Inoculants favored silage crude protein (CP) concentration, the smallest value $(6.23 \%)$ being observed in control silage. It was also observed an effect of fermentation period on neutral detergent fiber (NDF) and acid detergent fiber (ADF), which decreased by 0.302353 and 0.063321 units/fermentation day, respectively. The in vitro dry matter digestibility increased with fermentation period, with increments of 0.0546305 unit/ day. In the second experiment, intake and total apparent digestibility of silage nutrients were evaluated with rams. Eighteen castrated adult rams were assigned to three treatments, in a randomized blocks design, with six replicates. The diets consisted of 90:10 forage to concentrate ratio in a dry matter basis. The intake of nutrients was not influenced by the experimental diets, being observed mean values of $1.26 ; 0.14$ and $0.84 \mathrm{~kg}$ /day for dry matter (DM), crude protein intake (CP) and total digestive nutrients (TDN) intake, respectively. An inoculant effect was observed on CP apparent digestibility, greater value being observed for silage treated with the Biomax inoculant $(66.0 \%)$. The inoculant addition to corn plant changed nor silage chemical composition, neither the intake of its nutrients by the animal.

Key Words: ammonia nitrogen, digestibility, intake, $\mathrm{pH}$ 


\section{Introdução}

Os principais microrganismos relacionados à deterioração da silagem são os fungos, com destaque para as leveduras, e as bactérias do gênero Bacillus (Woolford, 1990). As leveduras são favorecidas pelo emurchecimento no campo, principalmente aquelas que utilizam ácidos como fonte de energia, e podem ficar dormentes dentro do silo até que seja aberto e o ar entre novamente na massa ensilada. Entretanto, uma rápida fermentação pode atenuar consideravelmente essa situação de dormência e de crescimento de algumas leveduras, pois o ácido produzido age como inibidor de leveduras que utilizam lactato (Johnson \& Pahlow, 1981; Pahlow \& Honig, 1986, citados por Woolford, 1990). Essa inibição pode ser causada pelo efeito sinérgico entre uma produção de ácido lático suficiente para diminuir o $\mathrm{pH}$ até 4,0 e pelo uso do oxigênio pelas bactérias ácido-láticas homofermentativas, produzindo também ácido lático (Moon, 1983, citado por Woolford, 1990).

Portanto, o uso de aditivos microbianos consiste em importante recurso, pois contribui para a redução da proteólise enzimática, resultante do rápido decréscimo do pH da massa ensilada, favorecendo a produção de grandes quantidades de ácido lático, o que representa a possibilidade de maior recuperação da matéria seca ensilada (Henderson, 1993).

Dietas contendo silagens produzidas com inoculantes microbianos têm promovido pequenos aumentos no consumo de matéria seca e na digestibilidade de nutrientes, resultando em melhor utilização da energia (Kung Jr., 1996), podendo, inclusive, melhorar o desempenho animal (Muck, 1993).

Vários autores tentaram elucidar como as silagens produzidas com inoculantes microbianos resultam direta ou indiretamente em maiores palatabilidade, consumo e digestibilidade. Os resultados positivos devem-se provavelmente aos efeitos probióticos destes produtos ou a outros efeitos não-mensuráveis (Kung Jr. \& Muck, 1997). $\mathrm{O}$ efeito probiótico inibe microrganismos prejudiciais à fermentação dentro do silo, além de promover benefícios às floras ruminal e intestinal de ruminantes, favorecendo o aproveitamento dos nutrientes da dieta (Weinberg \& Muck, 1996). Entretanto, Dewhurst et al. (2000) destacaram que não existe efeito consistente relacionando o uso desses aditivos em silagens com vantagens adicionais à produção microbiana ruminal.

Objetivou-se com este trabalho analisar a composição química, o pH, a relação nitrogênio amoniacal/nitrogênio total e a digestibilidade in vitro da matéria seca de silagens de milho, produzidas ou não com inoculantes enzimobacterianos, bem como avaliar o consumo e a digestibilidade aparente total de seus nutrientes em ensaio com ovinos.

\section{Material e Métodos}

Experimento 1-Composição química e digestibilidade in vitro de silagens de milho produzidas com inoculantes enzimo-bacterianos

O experimento foi conduzido no Laboratório Animal do Departamento de Zootecnia, da Universidade Federal de Viçosa (UFV), em Viçosa - MG, no período de 12 de março a 07 de maio de 2002. A cidade de Viçosa está situada a $20^{\circ}$ e $45^{\prime}$ de latitude sul, $42^{\circ}$ e $51^{\prime}$ 'de longitude oeste e $657 \mathrm{~m}$ de altitude e apresenta precipitação média anual de $1.341 \mathrm{~mm}$, dos quais cerca de $86 \%$ ocorrem nos meses de outubro a março. A temperatura média das máximas é de $26,1^{\circ} \mathrm{C}$ e a média das mínimas é de $14,0^{\circ} \mathrm{C}$ (Ministério da Agricultura, 1961). O clima da região é classificado como "Cwa", segundo classificação proposta por Köepen (1948).

Utilizou-se um arranjo fatorial $6 \times 3$, composto de seis períodos de fermentação $\mathrm{x}$ três inoculantes (um controle e dois inoculantes comerciais), em um delineamento inteiramente casualizado, com três repetições, para avaliação dos teores de matéria seca e proteína bruta, da relação nitrogênio amoniacal/nitrogênio total e do $\mathrm{pH}$. Para a avaliação dos constituintes fibrosos e da DIVMS, consideraram-se apenas quatro períodos (1, 14, 28 e 56 dias).

Oplantio do milho (AGROMEN 2012) foi feito em 13 de outubro de 2001, em área do Departamento de Zootecnia, utilizando-se o sistema de plantio direto. No plantio, aplicaram-se $350 \mathrm{~kg} / \mathrm{ha}$ da fórmula 8-28-16 e, como adubação de cobertura, utilizaram-se $200 \mathrm{~kg}$ /ha do adubo 20-0-20. O milho foi colhido aos 157 dias pós-semeadura, empregando-se uma máquina colhedora de forragem, modelo JF90.

Foram avaliados os inoculantes comerciais MAIZE ALL $^{\circledR}$, da Alltech do Brasil, contendo: Streptococcus (Enterococcus) faecium (10 bilhões ufc/g), Lactobacillus plantarum (10 bilhões ufc/g) e Pediococcus acidilactici (1 bilhão ufc/g), enzimas amilolíticas (2\%), enzimas celulolíticas $(1,5 \%)$ e dextrose e o BIOMAX ${ }^{\circledR}$, da Christian Hansen Biosystems contendo: Lactobacillus plantarum $\left(2,5 \times 10^{10} \mathrm{ufc} / \mathrm{g}\right)$, Pediococcus pentosaceus $\left(2,5 \times 10^{10} \mathrm{ufc} / \mathrm{g}\right)$, maltodextrina, aluminossilicatos e soro de leite, a $75 \%$. Foram adicionados 2 e $5 \mathrm{~g}$ dos inoculantes BIOMAX $^{\circledR} \mathrm{e}$ MAIZE ALL ${ }^{\circledR}$ por tonelada de forragem ensilada, diluídos em 2 e $1 \mathrm{~L}$, respectivamente, de água limpa, sem cloro, empregando-se um pulverizador com capacidade para $2 \mathrm{~L}$, respeitando-se as recomendações dos fabricantes. 
O material foi acondicionado em silos de PVC $(40 \mathrm{~cm}$ de altura e $10 \mathrm{~cm}$ de diâmetro), dotados de válvula de Bünsen e com capacidade para, aproximadamente, $2 \mathrm{~kg}$ de forragem, com base na matéria natural, efetuando-se a compactação com o auxílio de soquetes de madeira. Em seguida, os silos foram fechados, pesados e armazenados em área coberta, em temperatura ambiente, durante $1,3,7,14,28$ e 56 dias (períodos de fermentação).

Na ocasião da abertura dos silos, foram coletadas amostras, em cada silo, para determinações de pH e nitrogênio amoniacal/ $\mathrm{N}$ total (Bolsen et al., 1992). Para análise do $\mathrm{pH}$, foram coletadas subamostras de $25 \mathrm{~g}$ de silagem, que foram adicionadas de $100 \mathrm{~mL}$ de água destilada e mantidas em repouso por duas horas, fazendo-se, em seguida, a leitura do $\mathrm{pH}$. Outra subamostra de $25 \mathrm{~g}$ de silagem foi misturada a $200 \mathrm{~mL}$ de uma solução de $\mathrm{H}_{2} \mathrm{SO}_{4} 0,2 \mathrm{~N}$ e mantida em geladeira por 48 horas, efetuando-se, em seguida, a filtragem em papel-filtro do tipo "Whatman 54". O material filtrado permaneceu em geladeira até as análises de nitrogênio amoniacal, mediante destilação com hidróxido de potássio $(\mathrm{KOH}) 2 \mathrm{~N}$.

Concomitantemente, as amostras originais e suas respectivas silagens foram submetidas à pré-secagem a $65^{\circ} \mathrm{C}$, por 72 horas, em estufa de ventilação forçada. Em seguida, foram trituradas em moinho estacionário tipo "ThomasWilley" com peneira de $1 \mathrm{~mm}$ e acondicionadas em frascos de vidro com tampas de plástico para análises posteriores.

Os materiais originais e as silagens foram avaliados quanto aos teores de $\mathrm{MS}$ (em estufa a $105^{\circ} \mathrm{C}$ ), $\mathrm{PB}, \mathrm{FDN}$, FDA e DIVMS, segundo recomendações de Silva \& Queiroz(2002).

Os dados obtidos foram submetidos às análises de variância e regressão, utilizando-se o programa SAEG, versão 8.0 (Universidade Federal de Viçosa, 2000), e os fatores qualitativos, ao teste Tukey, a $5 \%$ de probabilidade, para comparação das médias. A escolha das equações de regressão foi feita com base no coeficiente de determinação e na significância dos coeficientes de regressão, utilizando-se o teste T. Para a avaliação do $\mathrm{pH}$, em função do período de fermentação, procedeu-se ao ajuste dos dados ao modelo não-linear: $f=y_{0}+[a x \exp (-b x)]$, proposto por Hristov \& McAllister(2002).

Experimento 2 - Consumo e digestibilidade de silagens de milho produzidas com inoculantes enzimo-bacterianos

Este experimento foi conduzido no Laboratório Animal, do DZO, da UFV, em Viçosa, MG, no período de 5 a 18 de julho de 2002, utilizando-se 18 ovinos adultos SRD, castrados, com peso médio de $48 \mathrm{~kg}$, distribuídos em um delineamento em blocos casualizados, com seis repetições.
Os tratamentos consistiram de silagens de milho produzidas com três inoculantes microbianos (um controle e dois comerciais), ensiladas em manilhas de concreto, com capacidade para $500 \mathrm{~kg}$ de forragem verde.

Os animais foram pesados, vermifugados, identificados com brincos no início do período experimental e mantidos em gaiolas para estudos metabólicos, em área coberta, com dispositivos para fornecimento de alimentos, água e mistura mineral. Ao final do período experimental, efetuou-se uma nova pesagem dos animais. Para a coleta de fezes, utilizaram-se sacolas especiais de napa adaptadas aos animais.

O experimento teve duração de 15 dias; dez para adaptação às dietas e cinco para coletas. Na primeira fase, os alimentos (silagem e concentrado) foram fornecidos à vontade e o consumo medido diariamente, considerando-se o consumo médio dos últimos três dias para fornecimento na fase de coletas. Os alimentos foram fornecidos diariamente às $7 \mathrm{~h}$ durante todo o período experimental. O concentrado consistiu de farelo de soja ( $46 \%$ PB), adicionado na proporção de $10 \%$ (na matéria seca) para todos os tratamentos.

A quantidade de alimentos fornecida a cada animal, na fase de coletas, foi $10 \%$ superior ao consumo médio observado na fase preliminar, de modo a possibilitar sobras. O consumo de alimentos foi mensurado diariamente, pela diferença de peso entre o alimento ofertado e as sobras. Nesta ocasião, foram realizadas amostras compostas dos alimentos fornecidos e das sobras, que foram acondicionadas em sacos plásticos e armazenadas em congelador para análises laboratoriais posteriores.

A coleta total de fezes foi realizada, diariamente, às 7 e 16 $\mathrm{h}$, registrando-se a quantidade diária de fezes excretadas por animal. Após a homogeneização do material, foi retirada uma alíquota diária de 5 a 10\%, para confecção de uma amostra composta por animal. As amostras de fezes foram acondicionadas em sacos plásticos e mantidas em congelador. Ao término do experimento, foram descongeladas à temperatura ambiente, pré-secas e armazenadas para análises posteriores.

Os teores de MS, MO, PB, EE e FDN dos alimentos fornecidos, das sobras e das fezes foram determinados conforme técnicas descritas por Silva \& Queiroz (2002). Nas silagens, também foram determinados o $\mathrm{pH}$ e o nitrogênio amoniacal/nitrogênio total, como no experimento 1 .

Os teores de $\mathrm{CHO}$ foram obtidos pela equação citada por Sniffen et al. (1992): $C H O(\% M S)=100-(\% P B+\% E E$ $+\%$ CINZAS). Para cálculo dos nutrientes digestíveis totais (NDT), utilizou-se a equação do NRC (2001): $N D T d=P B d$ $+2,25^{*} E E d+F D N c p d+C N F d$, em que PBd refere-se à proteína bruta digestível; EEd, ao extrato etéreo digestível; FDNcpd, à FDN digestível, corrigida para cinzas e proteína; e CNFd, a CNF. Os teores de CNF foram obtidos pela 
fórmula: $C N F=100-(\% P B+\% E E+\% F D N+\% C I N Z A S)$, proposta pelo NRC (2001).

Os dados de consumo e digestibilidade aparente total obtidos foram submetidos à análise de variância, comparando-se as médias pelo teste Tukey, a 5\% de probabilidade, utilizando-se o programa SAEG versão 8.0 (Universidade Federal de Viçosa-UFV, 2000).

\section{Resultados e Discussão}

Na Tabela 1 encontram-se a composição química e a digestibilidade in vitro da MS da planta de milho, antes da ensilagem. O teor médio de matéria seca $(39,6 \%)$ indica que o milho foi colhido com conteúdo de MS acima do recomendado (30 a 35\%) para ensilagem.

Observou-se efeito $(\mathrm{P}<0,05)$ da interação inoculante $\times$ período sobre o teor de MS das silagens (Tabela 2). No entanto, independentemente do período analisado, as silagens tratadas com inoculantes enzimo-bacterianos apresentaram teores de MS em função do período superiores aos encontrados para a silagem não tratada. Ao avaliar-se a variação de MS em função de período, observou-se efeito apenas na silagem controle, que se ajustou ao modelo: $\hat{\mathrm{Y}}=38,9829+0,138011^{*} \mathrm{P}-0,00235176^{*} \mathrm{P}^{2}\left(\mathrm{R}^{2}=68,25\right)$. Nas silagens tratadas com Maize All e Biomax, registraram-se, respectivamente, valores médios de MS de 43,3 e 43,1\%. Essas variações nos teores de MS provavelmente decorreram de problemas de amostragem, pois parece não haver alterações biológicas que justifiquem esse comportamento.

Verificou-se efeito $(\mathrm{P}<0,05)$ de inoculante sobre o teor de $\mathrm{PB}$, registrando-se valores médios de 6,3; 6,7 e 6,7\%, respectivamente, para a silagem controle e as tratadas com Maize All e Biomax, de modo que o teor de PB das silagens inoculadas foi superior $(\mathrm{P}<0,05)$ ao da não inoculada. Esse fato sugere menor proteólise nas silagens tratadas com inoculantes, resultando, portanto, em melhor conservação do teor protéico dessas silagens. Todavia, essa hipótese parece não ter fundamento, uma vez que a silagem tratada com Biomax apresentou maior valor de nitrogênio amoniacal/N total, por ocasião do último período de fermentação, em relação às outras silagens, conforme será apresentado posteriormente. Silva et al. (1997) também detectaram maior teor de PB em silagens de milho produzidas com inoculantes bacterianos.

Os teores de FDN e FDA foram influenciados $(\mathrm{P}<0,05)$ apenas pelos períodos de fermentação, ajustando-se aos modelos: $\hat{\mathrm{Y}}=67,9689-0,302353 * \mathrm{P}\left(\mathrm{r}^{2}=96,1\right)$ e $\hat{\mathrm{Y}}=28,1037$ $-0,0644724 * \mathrm{P}\left(\mathrm{r}^{2}=51,4\right)$, respectivamente. A redução da fração fibrosa nessas silagens deve-se, provavelmente, à hidrólise ácida da hemicelulose, que, segundo Muck (1993), resulta em ruptura das células da forragem, favorecendo ataque mais extensivo pelos microrganismos ruminais. Essa hipótese se justifica pelo fato de que as variáveis FDN e FDA não foram influenciadas pelo fator inoculante. Silva (2001), avaliando silagens de milho e de sorgo submetidas ao tratamento com inoculantes microbianos, verificou efeito $(\mathrm{P}<0,05)$ quadrático de período sobre o teor de FDN, estimando valores mínimos de 51,08 e 50,75\%, aos 37,63 e 46,05 dias de fermentação, para silagens produzidas com Silobac e Maize All, respectivamente. O teor de FDA, por sua vez, foi influenciado somente na ausência de inoculante, estimando valor mínimo de 30,27\% aos 25,35 dias de fermentação. Phillip \& Feller (1992) e Kung Jr. \& Ranjit (2001) também não constataram respostas positivas da adição de inoculantes microbianos contendo ou não enzimas sobre a redução da fração FDN em silagens de milho.

A exemplo das frações fibrosas das silagens, a digestibilidade in vitro da matéria seca foi influenciada $(\mathrm{P}<0,05)$ apenas pelo período de fermentação, ajustando-se à equação $\hat{Y}=64,9264+0,0546305 * \mathrm{P}\left(\mathrm{r}^{2}=98,5\right)$. Silva (2001) estimou valores máximos de DIVMS de silagens de milho produzidas com os inoculantes Silobac e Maize All

Tabela 1 - Composição química e digestibilidade in vitro da matéria seca na planta de milho

Table 1 - Chemical composition and in vitro dry matter digestibility of corn plant

\begin{tabular}{lccccc}
\hline & MS (\%) & PB & FDN & FDA & DIVMS \\
& DM (\%) & $C P$ & $N D F$ & $A D F$ & IVDMD \\
\cline { 3 - 6 } & & \multicolumn{5}{c}{$\begin{array}{c}\text { } \% \text { MS } \\
\end{array}$} \\
\cline { 3 - 6 } $\begin{array}{l}\text { Milho } \\
\text { Corn }\end{array}$ & 39,6 & 7,45 & 56,9 & 24,8 & 63,0 \\
\hline
\end{tabular}

Tabela 2 - Teores médios de matéria seca de silagens de milho, inoculadas ou não, nos diferentes períodos de fermentação

Table 2 - $\quad$ Average dry matter contents of corn silages with or without inoculants in different fermentation periods

\begin{tabular}{lccc}
\hline & \multicolumn{3}{c}{$\begin{array}{c}\text { Inoculante } \\
\text { Inoculant }\end{array}$} \\
\cline { 2 - 4 } Período (dias) & $\begin{array}{c}\text { Controle } \\
\text { Control }\end{array}$ & $\begin{array}{c}\text { Maize All } \\
\text { Maize All }\end{array}$ & $\begin{array}{c}\text { Biomax } \\
\text { Biomax }\end{array}$ \\
\hline 1 & $39,7 \mathrm{~b}$ & $43,9 \mathrm{a}$ & $44,2 \mathrm{a}$ \\
3 & $38,8 \mathrm{~b}$ & $43,1 \mathrm{a}$ & $43,0 \mathrm{a}$ \\
7 & $39,4 \mathrm{~b}$ & $42,8 \mathrm{a}$ & $43,7 \mathrm{a}$ \\
14 & $41,1 \mathrm{~b}$ & $42,9 \mathrm{a}$ & $43,5 \mathrm{a}$ \\
28 & $40,8 \mathrm{~b}$ & $44,0 \mathrm{a}$ & $43,2 \mathrm{a}$ \\
56 & $39,4 \mathrm{c}$ & $43,2 \mathrm{a}$ & $41,1 \mathrm{~b}$ \\
\hline
\end{tabular}

Médias seguidas de letras iguais, na mesma linha, não diferem a $5 \%$ de probabilidade, pelo teste Tukey.

Means followed by the same letter in a row do not differ by Tukey test, at $5 \%$ probability. 
próximos àqueles períodos de fermentação que resultaram em teores mínimos de FDN.

Observou-se efeito $(\mathrm{P}<0,05)$ de inoculante e de período sobre o $\mathrm{pH}$ das silagens. Na Figura 1, encontram-se as estimativas de $\mathrm{pH}$, de acordo com o período de fermentação das diferentes silagens. Estimaram-se taxas de decréscimos de 0,$681 ; 0,48443$ e 0,579 unidades por dia de fermentação no $\mathrm{pH}$ da silagens controle e daquelas produzidas com os inoculantes Maize-All e Biomax, respectivamente. Os valores de $\mathrm{pH}$ destas três silagens permitem classificá-las como de muito boa qualidade. Observa-se que as três silagens apresentaram valores de $\mathrm{pH}$ que permitem classificá-los como de boa qualidade. Rápida queda no $\mathrm{pH}$ e baixo $\mathrm{pH}$ final podem ajudar na redução da população de microorganismos deletérios à silagem, os quais produzem grande quantidade de ácidos acético e butírico.

Detectou-se efeito $(\mathrm{P}<0,05)$ da interação inoculante $\times$ período sobre a relação nitrogênio amoniacal/Ntotal (N-NH ${ }_{3} / \mathrm{Ntotal}$ (Tabela 3). No último dia de fermentação, registraram-se menores valores de $\mathrm{N}-\mathrm{NH}_{3} / \mathrm{Ntotal}$ para a silagem controle e aquela tratada com Maize All, que não diferiram entre si $(\mathrm{P}>0,05)$. Efeito do período de fermentação sobre a variação de $\mathrm{N}-\mathrm{NH}_{3} / \mathrm{N}$ total foi verificado somente nas silagens inoculadas com Maize All e Biomax, cujos dados se ajustaram aos modelos quadráticos (Figura 2), com valores máximos de 4,56 e 6,28\%, aos 45,68 e 45,89 dias de fermentação para as respectivas silagens. O teor de $\mathrm{N}-\mathrm{NH}_{3} /$ Ntotal da silagem controle não foi influenciado $(\mathrm{P}>0,05)$ pelo período de fermentação, estimando-se valor médio de 3,71\%. Esse comportamento não era esperado, apesar de não existir explicação lógica para o mesmo. Contudo, é importante destacar que os valores de $\mathrm{N}-\mathrm{NH}_{3} / \mathrm{Ntotal}$ estimados para as silagens são baixos, permitindo

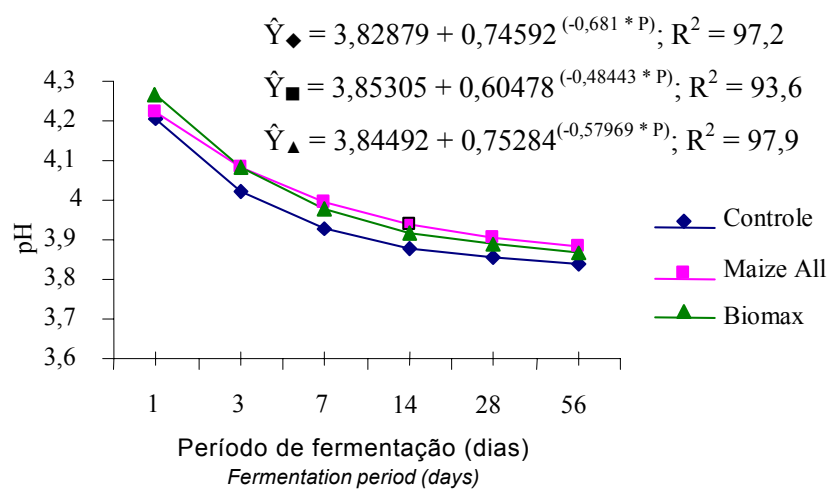

Figura 1 - Efeito do período de fermentação $(P)$ sobre o $\mathrm{pH}$ de silagens de milho produzidas com inoculantes enzimobacterianos.

Figure 1 - Effect of fermentation period $(P)$ on $p H$ estimate of corn silages with enzymatic-bacterial inoculants. classificá-las como de excelente qualidade, segundo classificação proposta por Wernli \& Ojeda (1990). A rápida queda no pH e sua manutenção a baixos valores limitam a ocorrência de grandes taxas de proteólise, resultando em melhorpreservaçãodaproteína da forragemensilada. Silva(2001) não observou diferenças entre os teores de $\mathrm{N}-\mathrm{NH}_{3} / \mathrm{N}$ total

Tabela 3 - Valores médios de $\mathrm{N}-\mathrm{NH}_{3} /$ Ntotal de silagens de milho produzidas com inoculantes enzimo-bacterianos, nos diferentes períodos de fermentação

Table 3 - Means of $\mathrm{N}-\mathrm{NH}_{3} /$ total $\mathrm{N}$ of corn silages with enzymaticbacterial inoculants, in different fermentation periods

\begin{tabular}{lccc}
\hline & \multicolumn{3}{c}{$\begin{array}{c}\text { Inoculante } \\
\text { Inoculant }\end{array}$} \\
\cline { 2 - 4 } Período (dias) & $\begin{array}{c}\text { Controle } \\
\text { Control }\end{array}$ & $\begin{array}{c}\text { Maize All } \\
\text { Maize All }\end{array}$ & $\begin{array}{c}\text { Biomax } \\
\text { Biomax }\end{array}$ \\
\hline 1 & $2,65 \mathrm{a}$ & $1,46 \mathrm{~b}$ & $1,81 \mathrm{ab}$ \\
3 & $3,06 \mathrm{a}$ & $2,18 \mathrm{a}$ & $2,44 \mathrm{a}$ \\
7 & $3,82 \mathrm{a}$ & $2,77 \mathrm{~b}$ & $2,95 \mathrm{ab}$ \\
14 & $3,78 \mathrm{a}$ & $3,15 \mathrm{a}$ & $3,56 \mathrm{a}$ \\
28 & $4,23 \mathrm{~b}$ & $4,00 \mathrm{~b}$ & $5,88 \mathrm{a}$ \\
56 & $4,68 \mathrm{~b}$ & $4,43 \mathrm{~b}$ & $6,01 \mathrm{a}$ \\
\hline
\end{tabular}

Médias seguidas de letras iguais, na mesma linha, não diferem a $5 \%$ de probabilidade, pelo teste Tukey.

Means followed by the same letter in a row do not differ by Tukey test, at $5 \%$ probability

Tabela 4 - Composição química das silagens de milho e do farelo de soja

Table 4 - Chemical composition of corn silages and soybean meal

\begin{tabular}{|c|c|c|c|c|}
\hline \multirow[b]{2}{*}{$\begin{array}{l}\text { Itens } \\
\text { Itens }\end{array}$} & \multicolumn{3}{|c|}{$\begin{array}{l}\text { Silagem } \\
\text { Silage }\end{array}$} & \multirow[b]{2}{*}{$\begin{array}{l}\text { Farelo de soja } \\
\text { Soybean meal }\end{array}$} \\
\hline & $\begin{array}{c}\text { Controle } \\
\text { Control }\end{array}$ & $\begin{array}{c}\text { Maize All } \\
\text { Maize All }\end{array}$ & $\begin{array}{c}\text { Biomax } \\
\text { Biomax }\end{array}$ & \\
\hline $\begin{array}{l}\text { MS (\%) } \\
D M(\%)\end{array}$ & 38,1 & 39,5 & 40,5 & 87,3 \\
\hline $\begin{array}{l}\mathrm{MO}^{1} \\
O M^{1}\end{array}$ & 95,8 & 95,9 & 96,0 & 93,2 \\
\hline $\begin{array}{l}\mathrm{PB}^{1} \\
C P^{1}\end{array}$ & 6,7 & 6,5 & 6,6 & 49,4 \\
\hline $\begin{array}{l}\mathrm{EE}^{1} \\
E E^{1}\end{array}$ & 3,0 & 3,0 & 2,9 & 2,5 \\
\hline $\begin{array}{l}\mathrm{CHO}^{1} \\
T C^{l}\end{array}$ & 86,5 & 86,8 & 86,8 & 43,3 \\
\hline $\begin{array}{l}\mathrm{FDN}^{1} \\
N D F^{l}\end{array}$ & 43,1 & 44,2 & 42,8 & 10,7 \\
\hline $\begin{array}{l}\mathrm{FDA}^{1} \\
A D F^{l}\end{array}$ & 22,9 & 23,2 & 23,8 & 11,2 \\
\hline $\begin{array}{l}\text { Celulose } \\
\text { Cellulose }^{1}\end{array}$ & 17,3 & 18,5 & 26,0 & 5,7 \\
\hline $\begin{array}{l}\text { Hemicelulose } \\
\text { Hemicellulose }\end{array}$ & 23,4 & 22,3 & 22,6 & 4,6 \\
\hline $\begin{array}{l}\text { Lignina } \\
\text { Lignin }^{1}\end{array}$ & 4,8 & 4,0 & 5,4 & 0,7 \\
\hline $\begin{array}{l}\mathrm{NIDN}^{2} \\
N D I N^{2}\end{array}$ & 0,3 & 0,47 & 3,2 & 0,5 \\
\hline $\mathrm{pH}$ & 3,96 & 4,05 & 4,11 & \\
\hline $\begin{array}{l}\mathrm{N}-\mathrm{NH}_{3} / \text { Ntotal } \\
\mathrm{N}-\mathrm{NH}_{3} / \text { Total } N\end{array}$ & 7,23 & 7,61 & 6,96 & \\
\hline
\end{tabular}

$1 \%$ de MS.

$2 \%$ de FDN.

$1 \%$ of dry matter.

$2 \%$ of NDF. 
em silagens de milho tratadas com inoculantes bacterianos, porém estimou valor máximo aos 41,48 dias de fermentação, próximo ao encontrado neste estudo.

A composição química das silagens e do farelo de soja e os valores de $\mathrm{pH}$ e nitrogênio amoniacal/Ntotal das silagens são apresentados na Tabela 4. Considerando-se o $\mathrm{pH}$ e na relação $\mathrm{N}-\mathrm{NH}_{3} /$ Ntotal dessas silagens, pode-se considerá-las de excelente qualidade.

$\mathrm{Na}$ Tabela 5 constam os consumos médios dos nutrientes e seus respectivos coeficientes de variação. Os inoculantes não influenciaram $(\mathrm{P}>0,05)$ os consumos dos nutrientes, observando-se valores médios de 1.260,9; $1.208,6 ; 137,8 ; 36,1 ; 514,7 ; 1.036,8$ e $843,1 \mathrm{~g} /$ dia para MS, MO, PB, EE, FDN, CHO e NDT, respectivamente. Rodrigues et al. (2002) também não verificaram efeito da adição do inoculante Pioneer 1174 sobre o consumo de nutrientes de silagens de milho, em ensaios com ovinos. Luther (1986), em ensaio com bovinos alimentados com dietas contendo $90 \%$ de silagem de milho e $10 \%$ de concentrado (na matéria seca), também não constatou efeito do inoculante microbiano sobre o consumo de matéria seca. Kung Jr. \& Muck (1997), revisando trabalhos publicados de 1990 a 1995 , encontraram respostas positivas dos inoculantes microbianos sobre o consumo, o ganho de peso e a produção de leite em 28,53 e $47 \%$ dos estudos, respectivamente. Esses resultados, embora animadores, devem ser interpretados com alguns cuidados, pois os inoculantes não são os mesmos e as condições (taxa de aplicação, cultura, umidade) variam bastante entre os estudos.

Tabela 5 - Consumos médios de MS, MO, PB, EE, FDN, CHO eNDT das silagens de milho produzidas com inoculantes enzimo-bacterianos

Table 5 - $\quad$ Mean intakes of DM, OM, CP, EE, NDF, TC and TDN of corn silages produced with enzymatic-bacterial inoculants

\begin{tabular}{|c|c|c|c|c|}
\hline \multirow[b]{2}{*}{$\begin{array}{l}\text { Itens } \\
\text { Itens }\end{array}$} & \multicolumn{3}{|c|}{$\begin{array}{l}\text { Inoculante } \\
\text { Inoculant }\end{array}$} & \multirow[b]{2}{*}{ CV (\%) } \\
\hline & $\begin{array}{c}\text { Controle } \\
\text { Control }\end{array}$ & $\begin{array}{c}\text { Maize All } \\
\text { Maize All }\end{array}$ & $\begin{array}{l}\text { Biomax } \\
\text { Biomax }\end{array}$ & \\
\hline \multicolumn{5}{|c|}{$\begin{array}{l}\text { Consumo (g/dia) } \\
\text { Intake (g/day) }\end{array}$} \\
\hline $\mathrm{MS}(D M)$ & 1371,5 & 1109,3 & 1302,0 & 16,9 \\
\hline $\mathrm{MO}(O M)$ & 1313,3 & 1063,3 & 1249,1 & 16,9 \\
\hline $\mathrm{PB}(C P)$ & 147,3 & 125,6 & 140,6 & 14,1 \\
\hline $\mathrm{EE}(E E)$ & 38,8 & 33,3 & 37,2 & 12,7 \\
\hline $\mathrm{FDN}(N D F)$ & 530,6 & 510,9 & 502,5 & 15,0 \\
\hline $\mathrm{CHO}(T C)$ & 1127,5 & 907,9 & 1075,0 & 17,4 \\
\hline $\mathrm{NDT}(T D N)$ & 874,3 & 774,5 & 880,4 & 15,3 \\
\hline \multicolumn{5}{|c|}{$\begin{array}{c}\text { Consumo }(\% \mathrm{PV}) \\
\text { Intake }(\% \quad B W)\end{array}$} \\
\hline $\operatorname{MS}(D M)$ & 2,81 & 2,39 & 2,75 & 15,7 \\
\hline $\mathrm{MO}(O M)$ & 2,69 & 2,29 & 2,63 & 15,7 \\
\hline $\mathrm{FDN}(N D F)$ & 1,06 & 1,08 & 1,04 & 13,7 \\
\hline
\end{tabular}

Os valores médios de digestibilidade da FDN e digestibilidade aparente total dos demais nutrientes das silagens encontram-se na Tabela 6 . Somente a digestibilidade aparente da proteína bruta foi influenciada $(\mathrm{P}<0,05)$ pelos inoculantes, registrando-se maior valor para a silagem produzida com o inoculante Biomax. Rodrigues et al. (2002), em silagem de milho produzida com o inoculante Pioneer 1174, não verificaram efeito da inoculação sobre a digestibilidade aparente dos nutrientes avaliados. Segundo Keady et al. (1994), o inoculante bacteriano pode aumentar a digestibilidade das silagens sem afetar os consumos de MS e ED. Considerando-se a relação direta entre consumo e digestibilidade (Baile \& Forbes, 1974, citados por Forbes, 1993), pode-se inferir que a ausência de efeito de inoculante sobre a digestibilidade da maioria dos nutrientes é decorrente da ausência de efeito do inoculante sobre o consumo dos nutrientes.

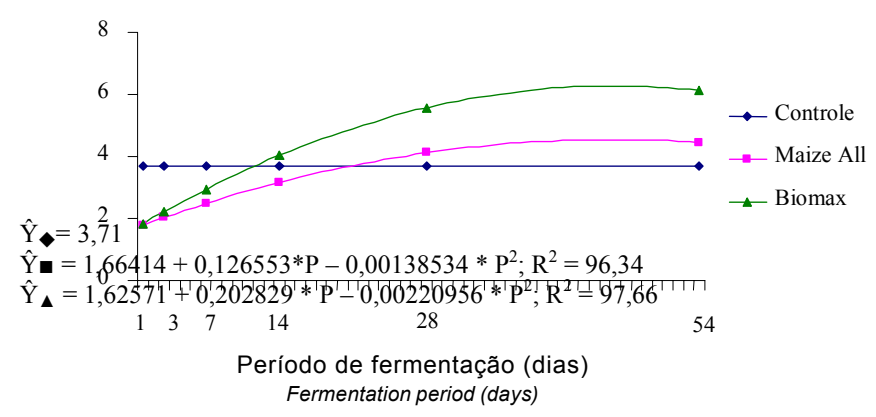

Figura 2 - Efeito do período de fermentação (P) sobre a estimativa da relação nitrogênio amoniacal/Ntotalde silagens de milho produzidas com inoculantes enzimo-bacterianos.

Figure 2 - Effect of fermentation period $(P)$ on ammonia nitrogen/total $N$ estimate of corn silages with enzymatic-bacterial inoculants.

Tabela 6 - Digestibilidades aparentes médias (\%) de MS, MO, EE, PB e digestibilidade da FDN das silagens de milho produzidas com inoculantes enzimo-bacterianos

Table 6 - $\quad$ Average apparent digestibilities (\%) of DM, OM, EE, CPand NDF digestibility of corn silages with enzymatic-bacterial inoculants

\begin{tabular}{lcccr}
\hline & \multicolumn{3}{c}{$\begin{array}{c}\text { Inoculante } \\
\text { Inoculant }\end{array}$} \\
\cline { 2 - 4 } Itens & $\begin{array}{c}\text { Controle } \\
\text { Itens }\end{array}$ & $\begin{array}{c}\text { Maize All } \\
\text { Control }\end{array}$ & $\begin{array}{c}\text { Biomax All } \\
\text { Biomax }\end{array}$ & CV (\%) \\
\hline MS (DM) & 60,4 & 54,8 & 61,2 & 8,35 \\
MO (OM) & 62,2 & 56,9 & 62,9 & 7,70 \\
EE (EE) & 89,0 & 89,2 & 90,0 & 4,69 \\
PB (CP) & 60,5 b & 59,2 b & 66,0 a & 4,54 \\
FDN (NDF) & 35,17 & 37,21 & 37,35 & 20,27 \\
\hline
\end{tabular}

Médias seguidas de letras iguais, na mesma linha, não diferem a $5 \%$ de probabilidade pelo teste Tukey.

Means followed by the same letter in a row do not differ by Tukey test, at $5 \%$ probability. 


\section{Conclusões}

Considerando-se os valores de $\mathrm{pH}$ e nitrogênio amoniacal/Ntotal, as silagens produzidas podem ser consideradas de boa qualidade. Contudo, a adição de inoculantes à planta de milho não promoveu alterações na composição química e no consumo dos nutrientes das silagens.

\section{Literatura Citada}

BOLSEN, K.K.; LIN, C.; BRENT, B.E. et al. Effect of silage additives on the microbial succession and fermentation process of alfalfa and corn silages. Journal of Dairy Science, v.75, n.11, p.3066-3083, 1992.

DEWHURST, R.J.; DAVIES, D.R.; MERRY, R.J. Microbial protein supply from the rumen. Animal Feed Science and Technology, v.85, p.1-21, 2000.

HENDERSON, N. Silage additives. Animal Feed Science and Technology, v.45, p.35-56, 1993.

FORBES, J.M. Voluntary feed intake. In: FORBES, J.M.; FRANCE, J.(Eds.). Quantitative aspects of ruminant digestion and metabolism. Cambridge: University Press, 1993. p.479-494.

HRISTOV, A.N.; McALLISTER, T.A. Effect of inoculants on wholecrop barley silage fermentation and dry matter disappearance in situ. Journal of Animal Science, v.80, p.510-516, 2002.

KÖEPPEN, W. Climatologia. Buenos Aires: Panamericana, 1948. $478 \mathrm{p}$.

KEADY, T.W.J.; STEEN, R.W.J.; KILPATRICK, D.J. et al. Effects of inoculant treatment on silage fermentation, digestibility and intake by growing cattle. Grass Forage Science, v.49, n.2, p.284-294, 1994.

KUNG JR., L. Use of additives in silage fermentation. In: Directfed microbial, enzyme and forage additive compendium. 1996. p.37-42.

KUNG JR., L.; MUCK, R. E. Animal response to silage additives. In: SILAGE: FIELD TO FEEDBUNK-NORTH AMERICAN CONFERENCE, 1997, Hershey. Proceedings... New York: NRAES-99, 1997. p.200-210.

KUNG JR., L.; RANJIT, N.K. The effect of Lactobacillus buchneri and other additives on the fermentation and aerobic stability of barley silage. Journal of Dairy Science, v.84, n.5, p.1149$1155,2001$.

LUTHER, R.M. Effect of microbial inoculation of whole plant corn-silage on chemical characteristcs preservation and utilization by steers. Journal of Animal Science, v.63, n.5, p.1329-1336, 1986

MINISTÉRIO DA AGRICULTURA - MA. Escritório de meteorologia. Normas climáticas. Viçosa, 1961

MUCK, R.E. The role of silage additives in making high quality silage. In: SILAGE PRODUCTION FROM SEED TO ANIMAL, 67., 1993, New York. Proceedings... New York: NRAES, 1993. p.106-116.

NATIONAL RESEARCH COUNCIL - NRC. Nutrient requirements of dairy cattle. 7.ed. Washington, D.C.: National Academy Press, 2001. 381p.
PHILLIP, L.E.; FELLNER, V. Effects of bacterial inoculation of hig-moisture ear corn on its aerobic stability, digestion and utilization for growth by beef steers. Journal of Animal Science, v.70, n.10, p.3178-3187, 1992.

RODRIGUES, P.H.M.; ANDRADE, S.J.T.; RUZANTE, J.M. et al. Valor nutritivo da silagem de milho sob o efeito da inoculação de bactérias ácido-láticas. Revista Brasileira de Zootecnia, v.31, n.6, p.2380-85, 2002.

SILVA, A.V. Populações microbianas em plantas de milho e sorgo, produtos da fermentação e desempenho de bovinos de corte, suplementados com suas silagens, tratadas com inoculantes microbianos. Viçosa, MG: Universidade Federal de Viçosa, 2001. 122 p. Tese. (Doutorado em Zootecnia) Universidade Federal de Viçosa, 2001

SILVA, D.J.; QUEIROZ, A.C. Análise de alimentos: métodos químicos e biológicos. 3.ed. Viçosa, MG: Universidade Federal de Viçosa, 2002. 235p.

SILVA, L.F.P.; MACHADO, P.F. Qualidade da silagem de milho produzida no Brasil. Nota/ESALQ. Piracicaba, n.10 e 12, 1997.

SNIFFEN, C.J.; O'CONNOR, J.D.; Van SOEST, P.J. et al. A net carbohydrate and protein system for evaluating cattle diets: II. Carbohydrate and protein availability. Journal of Animal Science, v.70, p. 3562-3577, 1992.

UNIVERSIDADE FEDERAL DE VIÇOSA - UFV. Departamento de Engenharia Agrícola. Estação Meteorológica. Viçosa: 2002. n. p.

UNIVERSIDADE FEDERAL DE VIÇOSA - UFV. SAEG - Sistema de análises estatísticas e genéticas. Versão 8.0. Viçosa, MG: 2000. 150p. (Manual do usuário).

WEINBERG, Z.G.; MUCK, R.E. New trends and opportunities in the development and use of inoculants for silage. FEMS Microbiology Reviews, v.19, n.1, p.53-68, 1996.

WERNLI, C.; OJEDA, F. Metodologías para investigaciones sobre conservacion y utilization de ensilajes. In: WERNLI, C.; OJEDA, F. (Eds.) Nutrición de rumiantes: guia metodológica de investigación. San José: IICA, 1990. p.179-218.

WOOLFORD, M.K. The silage fermentation. New York: Marcel Dekker, 1984. 350p.

WOOLFORD, M.K. The detrimental effects of air on silage. Journal of Applied Bacteriology, v.68, p.101-116, 1990. 